\title{
EXAMINE THE ROLE OF THE MEDIA IN BUILDING TRUST AMONG PETROCHEMICAL STOCK SHAREHOLDERS
}

\author{
Maryam Ahmadi Ahangar \\ MA, Social Communications. Department of Communication, Islamic Azad University, Maybod \\ Branch, Maybod, Iran \\ Mahmadi@bipc.org.ir \\ Ali Mohammad Mazidi Sharafabadi \\ Department of Communication, Islamic Azad University, Maybod Branch, Maybod, Iran \\ Mazidi6@yahoo.com
}

\begin{abstract}
Petrochemical companies operate titled as the chemical industry that today is the largest exchange industry. Given the importance of the economy and stock market, and also a special place of Petrochemicals stock in Iranian stock exchange, this study was to investigate the effects of media on Trust shareholders on stock of petroleum. In this study, the data collection is done for research and hypotheses, given the nature of the subject (Survey), approved questionnaires are used and the necessary information was collected. The study population included 300 Aban broker members, all of whom have bought petrochemical stocks, respectively. A sample was calculated using Cochran formula, $n=73$. In this study, descriptive and inferential statistical analysis was performed with SPSS software. The results showed: the media has influence on increasing the confidence of investors to enter the stock market (petrochemical stock). Published in the media's ads (related to the stock NPC) affects Trust shareholders petrochemical exchange. Speed news distribution of petrochemical exchange is effective on trust and petrochemical exchange shareholders. Media Training programs (broadcasts, educational, publishing articles, etc.) influence the trust of petrochemical stock shareholders. Providing stock status at the time of boom and bust by the media affects trust of petrochemical stock shareholders. At the end solutions were presented to optimize the use of media in order to boost petrochemical stock market.
\end{abstract}

Keywords: Media, confidence, shareholders, Petrochemicals stock

\section{INTRODUCTION}

Media is a social communication device that its vast circle has become increasingly large and in addition to the press, radio, television, as well as the World Wide Web. The current situation of the media is one of the main achievements of human progress and one of the most valuable means of public awareness that Sam joined the gathering at the position of key importance and applicants are being developed according to the requirements. The media as one of the most important symbols of transformation in the realm of human life, gradually plays the role and gains the strategic position and its complex with attractions and psychological effects - social, as a decisive factor is determining in all areas of public and private life have been raised. To understand the importance of the media's role as just that McLuhan refers to it as the anchor that Archimedes was to mobilize the world to follow (Media and social issues, 2012: 8). It is predicted that the value of petrochemical products in the world. 2018 will be equivalent to 791 billion dollars. As a result, in the years 2012 to 2018, a growth rate of $6.7 \%$ per year. Also, the amount of consumption, it is predicted that by 2018 this figure will reach 627 million tons, an increase of $4.5 \%$ in the year. So petrochemical companies in Iran could also play a role in this development. The chemical industry is now the largest petrochemical companies in the exchange industry operate. Petrochemical industry contributed most to the implementation of Article 44 of the constitution had been subsidiaries of privatization. As a result, about $99 \%$ of petrochemical companies have been privatized so far which caused enlargement of the 
industry in the stock market. The current value of this industry is currently in stock and 260 billion of 406 thousand Rials. This industry is about 19/49 percent of the total value of the stock market. The daily average trading value of this industry is $21 \%$ of the total daily trading value of the stock. In terms of profitability, the petrochemical industry Sugar industry grew by 2005 percent since the beginning of 2009 is already the second. In other words, the industry's performance over the last 4 years was about 14 times. Petrochemical companies as the chemical industry is today the industry's largest stock exchange, operate. The media due to its unique features and functionality can play an effective role in identifying and to investigate the factors influencing investment macro-economic, political, social - cultural and technological society, and through advertising, rapid publication of news, education as well as providing actual situation in stock has a profound effect on confidence or lack of confidence investors in stock. In this study on the role of media in building trust is examined to make better investment decisions. And given the importance of the industry and the petrochemical industry, this review is for the economy, particularly on the role of media in Trust focuses petrochemical shareholders. Given the importance of the economy and stock market. Also a special place in the NYSE stock Petrochemicals Iran This study was to investigate the effects of media on trust shareholders took stock of petroleum.

\section{LITERATURE REVIEW}

Today's news through the news media has the way home, and can be provided in a moment for everyone in the city and country and the world, it is the conqueror of time and space and sweeps social, political and national boundaries. The media functionality as well as other capabilities, is one of the essential elements of effective media in the labor market and investment has become (Media Studies, 2011: 134). Particular attention has been paid by investors to the media, because this way can dominate public opinion, and create a good market for their products. In the past, everything that manufacturers were offering was sold, but as manufacturers shifted to be a competitive market and in this case the media was used as a tool for Products produced. Different sectors of the economy of any country, which specifies the relationship between these sectors, the direction of its economy. Money market is a short-term funds and exchange market and the maximum maturity of a financial period (usually one year). In addition to Money market, the market capitalization position is the utmost importance. Capital market based on its characteristics, for long-term resources, provides the possibility of exchanging resources among holders of surplus resources, applicants' resources deficit. Capital market is closely related to the country's economic structure and it may represent strengths and weaknesses of the economic situation (Butler, 1992: 197-200).

Since the economic growth and development requires large investment and these investments can never be based on short-term funds market (money market), create a strong and efficient capital market infrastructure basic fundamental long-term financing plans each country's. Capital market provides a mechanism it is possible to equip a small savings based on economic capital investment that this is possible based on the optimal allocation of resources. In a healthy economy and the stock market dynamic through the sale of stock and Bonds to mobilize financial resources to pay, can foster a sense of partnership few people to direct their capital towards productive and commercial activities and steps This is a big step towards the implementation of the general policies of Article 44 of the constitution that Is based on social justice and poverty eradication.

Development of capital markets can play an important role in growth National income country. Released statistics show that Exchanges are developed in developed countries. Investment security in this country before everything for domestic and foreign investors to provide the stock exchange. Capital markets in the financial markets, which constitute money market as part of the economy, its function and if no logical relationship to other sectors, their work is likely problems and shortcomings in the mechanism. Our country's capital markets practice at Tehran Stock Exchange In short, although more than three decades of history behind it but in the last decade of his life that it was the most active, Fluctuations and ups and downs faced by this is the collection and market performance affected its relationship with other economic sectors. So that there is still great potential investment opportunities in the country, could not find its rightful place in the economic set has attracted only a small share of savings (Journal of Financial Accounting and Auditing, 2010: 142). 
The chemical industry is the largest industry in our country stock owned by the Petrochemical companies were formed. Petrochemical industry of industries and employment that as a feeder of other industrial sectors can as the engine of the economies in developing countries Plays a key role. The share of Iranian petrochemical industry in the global market from $1.1 \%$ in 1384 to $4.2 \%$ at the end of 2012 has reached accordingly, the share of Iran's petrochemical industry 181\% growth in the global market. Iran's petrochemical products are currently exported to 60 different countries; So that 13 per cent of the Indian subcontinent, Southeast Asia 23 percent, China 22\%, 18\% Far East, European countries and the Middle East, 19\% from 5\% Iran's exports accounted for. A variety of petrochemical products could be lost rings and no doubt countless industries to complete the development of related industries the industry is also in the supply of consumer goods and Meet the needs of our domestic industries play an important role. Iranian petrochemical industry in recent years. In the field of conventional products and basic petrochemicals achieved a huge success. So that, Petrochemical industry's share of GDP from 29/1 percent by the end of 2004 is reached to 5.1 percent at the end of 2011.

On the other hand the share of non-oil export petrochemical industry with growth of 48 percent reached to 37/2 percent in 2012 and the share of the industry's exports of industrial products $34 / 8$ to $46 / 5$ percent of that is representing growth of 34 percent. On the other hand, petrochemical stock market like any other market principles and the particular circumstances that by considering and implementing these basic principles can be invested and purchased and sale of equity and real understanding of the issues was also in stock. Basically, investors should do range reviews at the time of buying or selling shares because they are the most liquid assets are converted into shares. No matter if they are a series of factors to invest, the outcomes will not gain investment, the studies have shown that investors who with their trade speculation or the little interest they are risky transactions (Factors affecting the Tehran Stock Exchange, 2010: No. 164, 21).

In order to create security in the market to attract more FDI, it is necessary to invest macro factors affecting economic, Political, socio - cultural and technological investigated and with accurate depiction of the risks and potential returns appropriate decision and are carried by major investors. Each of these macro factors is separated into smaller components (Looqany, 1995: 197-210). The media due to its unparalleled features and capabilities plays an important role in identifying and studying the macro factors affecting investment, including economic, political, Socio - cultural and technological society, and through advertising, the rapid publication of news, education, as well as providing the actual situation stock have a profound impact on the confidence or lack of confidence investors in stock.

Given the importance of the economy and stock market, and also a special place of petrochemical exchange in the Iranian stock market, the aim of this study is that an effective step applied to the economic growth the country by identifying the characteristics of the audience petrochemical stock market, understanding the impact of each one of the roles of the media on investor confidence Petrochemical stock market, recognition of each of the Traditional and new media on investor confidence Petrochemical stock market and the overall role of the media In the field of business confidence and attract investors Petrochemical shareholders. After reviewing research studies on literature, Action to provide variables and conceptual models that Include:

Independent variables include: the roles and functions of different media (awareness, education, persuasion, entertainment, etc.) as the independent variable in this study.

Dependent variable petrochemical shareholder confidence in this research is considered as the dependent variable. The impact of the independent variable was analyzed on the dependent variable. 


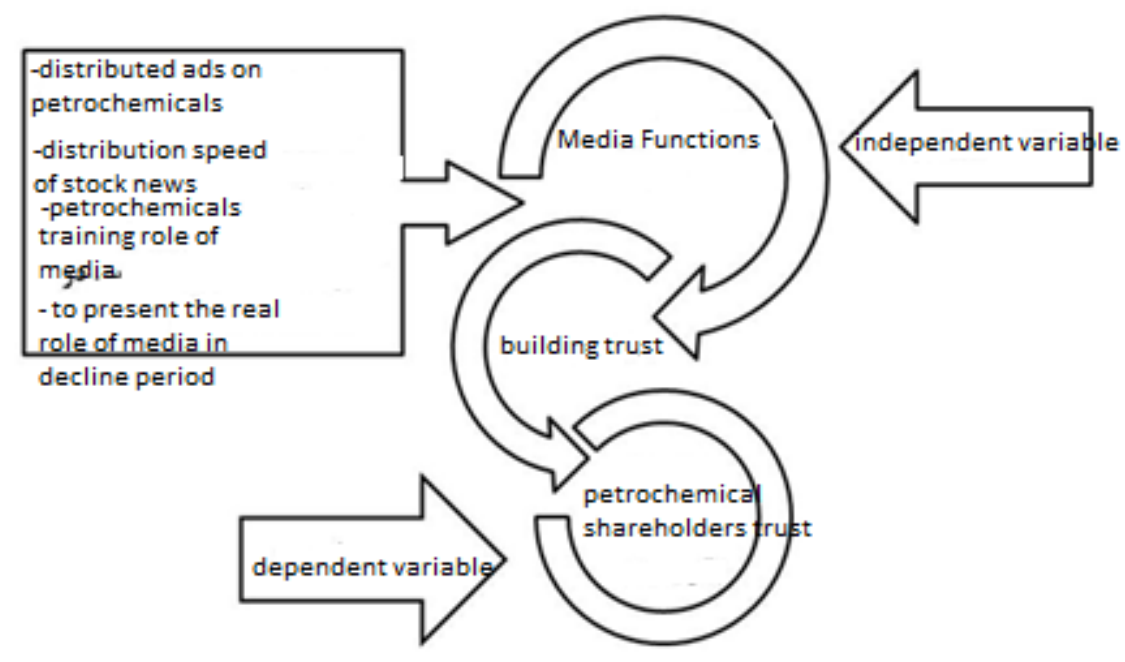

Fig. 1: Conceptual model of Research

Components of research in the following tables classified are observed according to studies in the literature study, based on a variety of media and media functions:

Table 1: Classification of component inventory based on media types

\begin{tabular}{|c|c|}
\hline Item number & $\begin{array}{c}\text { Components } \\
\text { Effects of books, journals and } \\
\text { magazines }\end{array}$ \\
\hline 5 & Effects of radio programs \\
\hline 5 & Effects of television programs \\
\hline 5 & Effects of material published on the \\
Internet \\
\hline 20
\end{tabular}

Table 2: Classification of components according to media functions questionnaire

\begin{tabular}{|c|c|}
\hline Item number & $\begin{array}{c}\text { Components } \\
\text { functions }\end{array}$ \\
\hline 5 & $\begin{array}{c}\text { Effects of a series of confidence-building } \\
\text { Effects of advertising on confidence-building } \\
\text { release }\end{array}$ \\
\hline 5 & $\begin{array}{c}\text { Effects of speed on confidence-building news } \\
\text { building }\end{array}$ \\
\hline 5 & Total on confidence- \\
\hline 20 & \\
\hline
\end{tabular}

\section{METHODOLOGY}

The choice of method depends on many criteria such as the type of research objectives, the nature of its research and administrative facilities. So it was decided about the kind of research when the nature of the research topic, objectives and scope of the investigation are known (Nader and Saif Naraqi, 1993, 59). 
Accordingly, the method used in this study can be examined from different aspects of the investigation. Based on the goal, this research is applied and based on the method of data collection, is descriptive and correlational. In this study, to collect the necessary information, both will be used to collect information through library study and collect information through a standard questionnaire developed by the researchers. The population in this study 300 investors brokerage firm November (limited) registration number of 124 074 Petrochemical stocks have chosen. The survey is based on random sampling. Cochran formula used to calculate the sample size will be. Cochran is one of the most widely used methods for calculating sample size. In this formula:

n: sample size

$\mathrm{N}$ : Statistical population size

t: percentage of acceptable standard error confidence

P: proportion of the population has a certain attribute

q: proportion of the population lacks certain traits

d: degree of certainty or potential efficiency

$$
n=\frac{N \cdot t^{2} \cdot(p \cdot q)}{\left(N \cdot d^{2}\right)+\left(t^{2} \cdot p \cdot q\right)}
$$

Formula 1: Cochran

In accordance with the following formula can be obtained for sample size $\mathrm{n}=73$, the population of the 300 members of the stock broker of Petrochemical stocks have purchased. (Assuming an acceptable error 10\%). Data was collected using the questionnaires and through interviews with respondents. After processing, editing and revisions, after its first three-dimensional questionnaire was developed which includes all individual investor and the second and third contains 20 questions in relation to the effect of media instances and the different roles, and the confidence of investors in the stock petrochemicals. The validity was confirmed by Professor Ali Mohamed MAZIDI Sharifabadi. The reliability was calculated using Cronbach's alpha coefficient. This means that before the final run, 30 of the sample were selected randomly were placed at their disposal, and after collecting the questionnaires, SPSS statistical software version 19 Cronbach's alpha coefficient was used to calculate and as a result, its value was obtained for the questionnaire study $0 / 808$ if the word is stability and internal consistency.

\section{RESULTS}

The analysis of data collected for statistical analysis presented in both descriptive and inferential statistics. First, using descriptive statistics and demographic characteristics of situational awareness and more in inferential statistics, this study examines the relationships between the variables analyzed in the study. To regulate and classify data based on the effects of media types and functions of different types of media were evaluated on shareholder confidence petrochemical, relevant responses. The results are presented in five sections:

1. The effects of the media: the trust of shareholders NPC to enter this market.

2. Effects of Advertising media types on the confidence of shareholders Petrochemicals

3. Effects spread news across all media types on the confidence of shareholders Petrochemicals

4. The effects of training programs on a variety of media, petrochemical shareholders confidence

5. Effect of exchange at the time of presenting the true position of boom and bust by a variety of media, the confidence of shareholders Petrochemicals

To gain the trust of each function, each of the qualitative values should be weighted in a questionnaire after valuation. In Table 3 values are valued and Qualitative responses weighted: 
Table 3: Weighted Average Data Rate and questionnaires

\begin{tabular}{|c|c|c|c|c|c|c|c|c|c|c|c|}
\hline \multicolumn{5}{|c|}{ average weight } & \multicolumn{5}{|c|}{ Frequency } & & \\
\hline very high & high & mean & low & very low & very high & high & mean & low & very low & & \\
\hline $.8 \times 7$ & $\varepsilon .0 \cdot \mathrm{V}$ & $\cdot 19$ &. $.1 \pi$ & $\therefore+\pi V$ & A & ¿v & IT & $T$ & $\tau$ & newapap & \\
\hline דזו. & 1.101 & T. NT & .211 & $\therefore u$ & 1 & ir & ¿o & 1. & 0 & radio & first \\
\hline 1.507 & 2.211 & תו &. $.1 \pi$ & $\because .00$ & 11 & हา & 4 & $T$ & $\varepsilon$ & TV & \\
\hline $0.2 \pi 0$ & $T .+1 \varepsilon$ & $\because T=0$ & .NT & $\because+\leqslant 1$ & $\varepsilon \varepsilon$ & TI & $T$ & $T$ & $T$ & Internet & \\
\hline ז & .904 & T.ETo &. .211 & $\because \mathrm{TV}$ & 1 & 1. & 0. & 1. & $\tau$ & newapape & er \\
\hline Tזו. & $.18 T$ & $1 . .87$ & 114 &. .11 & 1 & $T$ & in & 纟า & $\wedge$ & radio & $2 n$ \\
\hline דזו. & 1.101 & T. МN &. .211 & $\therefore u$ & 1 & it & ¿o & 1. & 0 & TV & \\
\hline .917 & $2.0 \cdot \mathrm{V}$ & $\cdot 19$ &. $.1 \pi$ & $\therefore+\mathrm{TV}$ & $\wedge$ & ¿v & it & $T$ & $T$ & Interne & \\
\hline זדו. &. .404 & T.T07 & $.2 Q T$ & $\ldots+1 \varepsilon$ & 1 & 1. & $\varepsilon 4$ & it & 1 & newapap & der \\
\hline . & . & $\cdot 19$ & $1.1 \leq 2$ & $.18 T$ & 1 & - & it & $\varepsilon_{0}$ & $1 \varepsilon$ & radio & 3rd functi \\
\hline $.2 A T$ & $\cdot$. TAE & $T .794$ & $\because T=0$ & . AT & $\varepsilon$ & $\varepsilon$ & $0 \&$ & 0 & 7 & TV & \\
\hline $0.7 \times 1$ & ורז & $.1 \pi$ & $.17 \varepsilon$ & $\because \leqslant 1$ & 纟า & in & $T$ & $\varepsilon$ & $T$ & Interne & \\
\hline זזו. & . T^E & $T \cdot Q \cdot \varepsilon$ & $.0 \pi$ & .11 & 1 & $\varepsilon$ & ov & $T$ & A & newapape & er \\
\hline 1.507 & 2.211 & &. $.1 \pi$ & $\because 00$ & 11 & 纟า & Q & $T$ & $\varepsilon$ & radio & \\
\hline 1.11 & 2.749 & $\cdot \pi \underline{\tau}$ & $\cdot T \cdot 0$ & $\therefore v$ & 4 & $\varepsilon Q$ & 0 & 0 & 0 & TV & . \\
\hline רות. & $2 . V Q_{0}$ & רור. & $\cdot T \varepsilon V$ & $\because+21$ & 0 & 0. & Q & 7 & $T$ & Interne & . \\
\hline $0.2 \pi 0$ & $\pi .+1 \varepsilon$ & $\because \pi=0$ & $\because N T$ & $\because \leqslant 1$ & $\varepsilon \varepsilon$ & TI & $T$ & $T$ & $T$ & newapap & der \\
\hline 1.11 & $\cdot T M$ & T.ETo &.$\pi v$ & $\because \pi V$ & 4 & $T$ & 0. & Q & $T$ & radio & $5+\mathrm{t}$ \\
\hline $.2 \times 7$ & $2 . V Q_{0}$ & .211 & יטt & $\therefore .87$ & A & 0. & 7 & $T$ & $v$ & TV & \\
\hline $0.7 \times 1$ & $1 . v \pi$ & $.1 \pi$ & $.17 \varepsilon$ & $\because+\leqslant 1$ & 纟า & in & $T$ & $\varepsilon$ & $T$ & Interne & \\
\hline
\end{tabular}

To check-test was used, based on the test for each of the hypotheses, alternative hypothesis was considered as below. And then get the t-statistic values in each case, to reject or accept the hypothesis were evaluated, the values of each of the five hypothesis $t$ given in Table 4:

1. There is a relationship between the role of the media and increase the confidence of investors to enter the stock market (petrochemicals).

2. There is a relationship between the releases of the media's ads (related to the stock NPC) and ensuring readers (the petrochemical stock shareholders).

3. There is a relationship between Petrochemical exchange and trust, the speed of news about the audience (shareholders stock petrochemicals).

4. There is a relationship between the role of media training (broadcasts, educational, publishing articles, etc.) and the audience Trust (NYSE shareholders petrochemicals).

5. There is a relationship between the presentation of the actual situation on the stock exchange boom and bust times by the media and the audience Trust (NYSE shareholders petrochemicals).

Table 4: t-statistic values for each of the 5 hypothesis

\begin{tabular}{|c|c|c|c|c|}
\hline \multicolumn{4}{|c|}{ t-statistic values } & $\begin{array}{c}\text { Research } \\
\text { Hypothesis }\end{array}$ \\
\hline Internet & TV & Radio & Newspaper & H1 \\
\hline 11.882 & 7.049 & 9.864 & 8.109 & H2 \\
\hline 18.679 & 9.864 & 2.419 & 12.476 & $\mathbf{H 3}$ \\
\hline 11.034 & 9.681 & 6.377 & 12.885 & $\mathbf{H 4}$ \\
\hline 6.345 & 6.046 & 7.049 & 9.342 & $\mathbf{H 5}$ \\
\hline 11.034 & 5.631 & 10.835 & 11.882 & \\
\hline
\end{tabular}




\section{CONCLUSION}

The results indicate that: newspapers and magazines, radio, television and the Internet have the high, medium, high and very high effect on investors' increased confidence to enter the stock market of petrochemicals. Advertising in newspapers and magazines, radio, television and the Internet has the medium, low, medium and high effect on confidence petrochemical exchange's shareholders. News spread quickly in newspapers and magazines, radio, television and the Internet to effect medium, low, medium and very high on confidence shareholders have Petrochemicals. Training programs, newspapers and magazines, radio, television and the Internet have the medium, high, high and high effect on confidence shareholders of Petrochemicals.

Providing stock status at the time of boom and bust by newspapers and magazines, radio, television and the Internet have a medium, high or very high effect. Petrochemicals are on shareholder confidence. In analyzing the effects of the functions of media types, the hypothesis is not accepted or discussed; based on the results obtained (Table 5), in analyzing each of the five hypotheses in this study, the value of $t$ in each of the four parts of assumptions mentioned (newspapers, radio, television and Internet) is higher than the critical value 1.67. As a result, there is not up to $99 \%$ reason to reject the hypothesis. Given the results obtained from Data Descriptive statistics and inferential statistics were investigated in relation to each of the hypotheses affect Media types and brokers on Petrochemical shareholder confidence. In data analysis, inferential statistics, the results of the valuation and weighting the data (Table 3), data Descriptive statistics (Table 4) were confirmed.

The results indicate that the media by its extensive functions has a profound effect on decisions of shareholders and Petrochemical stock market investors. Hence, it is suggested that industrialists use this powerful tool in order to progress and industry the country's economy forward. Careful and targeted planning should be used to educate and encourage people to invest Petrochemical stock market, enjoying extensive media facilities, advice that is responsible for the development of the economy.

\section{REFERENCES}

Thompson, John. B. (2001). Media and Modernity. Translation Owhadi, M. Soroush. Tehran.

Baliq, N. (2001). Radio and television programming instructions in the UK. Sound research and development. Tehran.

Karimi, S. (2003). media. Boostan-e-ketab. Qom.

Sabilan Ardestani, H. (2007). Radio and crisis management. Office of Radio Research. Tehran.

McLuhan, Herbert Marshall. (1998). To understand media. Translation Azeri, Said. Research and evaluation program Mtlah Islamic Republic of Iran Broadcasting.

Soltanifar, M. (2007). Analysis of the relationship between media and politics in different theories: media diplomacy. Strategic Research Institute. 10. Journal of Tehran.

Rezai binder, MR. (2003). Examine the role of the media in civic education and citizenship behaviors. Quarterly Islamic Republic of Iran Broadcasting (IRIB) Research and Evaluation. 33. Number of Tehran.

Rahbari, M. (2005). Media and accountability of government institutions. Islamic Republic of Iran Broadcasting (IRIB) Research and Evaluation. 41. Number of Tehran.

Ehrari, E. (2004). Controlled media's role in society. Quarterly Research and Evaluation. Islamic Republic of Iran Broadcasting. 37. Number of Tehran.

Islamic Propagation Office of Qom, Isfahan branch (2012). Media and social issues. Abstract National Conference on media and social issues.

Bykard, Robert. (2008). Media economy. David Heidari translated. Media Development Office. Tehran

Roushandel Arbatani, T. (2007). What is Media Manager. 9-19

Cultural Research Bureau. (2009). Media management. Tehran

Sarookhani, B. (2004). Persuasion, communication ends. Monthly Social Sciences. 93-115

Kung, L. (2010). Strategic management in the media. Translation Akbar cultural, AR Gharagozlou, Mary, born orator. Danzhh publication. Tehran

Mac Kvayl, D. (2006). Introduction of mass communication. Media Development Office. Tehran 
Aghaz, MH and Jafarnejad, SA (2006), cultural and media in cultural development. Cultural Engineering Conference Secretariat. Tehran.

Englis, Fred. (1998). Media theory. Translation Mahmoud Kashani truth. Sound and Vision Research Center. Tehran.

Sarookhani, B. (1990). Sociology of communication. Soroush publication. Tehran. 